\title{
LA REPRESENTACIÓN SOCIAL DE LOS PORTADORES DE SIDA O TUBERCULOSIS: UNA EXPERIENCIA DEL CUIDAR EN LA TERAPIA OCUPACIONAL.
}

\section{The social representation of the carriers of AIDS or tuberculosis: an experience of caring in occupational therapy.}

\author{
Ângela Maria Bittencourt Fernandes da Silva ${ }^{\mathrm{i}}$ \\ Fernanda Carvalho de Queiroz Mello ${ }^{\mathrm{ii}}$ \\ Nébia Maria Almeida de Figueiredo ${ }^{\text {iii }}$
}

\section{RESUMEN}

El presente trabajo se fundamenta en las bases teóricas de la atención en Terapia Ocupacional (TO) y en la teoría de la representación social. Desarrolladas en clientes con tuberculosis (TB) o SIDA, en un hospital universitario, evaluando visando la adherencia al tratamiento. La cuestión central de esta investigación es el carácter relacional entre el tratamiento y el portador de TB o SIDA. Así, se objetiva caracterizar como la TO puede contribuir con la adhesión al tratamiento. Algunas preguntas fueron contestadas:¿cómo es la organización de los clientes entorno de hechos que constituyen sus medios físico y social?; ¿`erá que la TO puede cuidar de estas personas? ¿la TO puede facilitar la adherencia al tratamiento? La estrategia para la producción de datos fue apoyada en Talleres de Creatividad, con 12 clientes, por medio de la actividad artística. Los pacientes hablaron de los sentimientos que surgen en la relación entre el desarrollo y la convivencia con sus enfermedades. Los resultados mostraron que la TO contribuye con la disminución de comportamientos agresivos facilitando la adhesión al tratamiento. La conclusión es que la TO, favorece a que las personas, se preparen para hacer frente a las reacciones adversas, provocando la adhesión al tratamiento

Palabras claves - Terapia Ocupacional, Representación Social, Tuberculosis Pulmonar, SIDA, Inclusión Social.

\footnotetext{
i Terapeuta Ocupacional, Doutoranda do Curso de Pós-Graduação em Clínica Médica, Setor de Ciências Pneumológicas, Universidade Federal do Rio de Janeiro,

abittenc@hucff.ufrj.br, 55.21.26213953, Rua Professor Edmundo March, 20 apto 403, Boa Viagem, Niterói, Rio de Janeiro, Brasil

${ }^{i i}$ Médica, Pós-doutorado em Medicina, Professora Adjunta da Faculdade de Medicina Universidade Federal do Rio de Janeiro. Pesquisadora do Programa Acadêmico de TB/Instituto Doenças do Tórax-IDT/Universidade Federal do Rio de Janeiro; Rede TB de Pesquisa,fcqmello@uninet.com.br

iii Enfermeira. Diretora da Faculdade de Enfermagem Alfredo Pinto, Doutora em Enfermagem pela Universidade Federal do Rio de Janeiro (UFRJ). Livre Docente em Administração de Enfermagem da Escola de Enfermagem Alfredo Pinto da Universidade Federal do Estado do Rio de Janeiro (EEAP/UNIRIO). Professora Titular de Fundamentos de Enfermagem da EEAP/UNIRIO.
} 


\begin{abstract}
This work builds upon the theories of care in Occupational Therapy (OT) and the theory of social representation. Developed in clients with tuberculosis (TB) and AIDS in a university hospital, aiming to assess adherence to treatment. The central question of this research is the relational character between the treatment and the carrier of TB or AIDS. That objectively characterized as the OT can help with treatment adherence. Some questions were answered: How is the organization of the customers' environment facts constituting their physical and social? Can it be that the OT can take care of these people? OT may facilitate adherence to treatment? The strategy for data production was supported in Creativity Workshops, with 12 clients, through artistic activity. Patients spoke of the feelings that arise in the relationship between development and living with their diseases. The results showed that the OT contributes with decrease of aggressive behavior by facilitating treatment compliance. The conclusion is that the OT, encourages people to prepare to cope with adverse events causing treatment adherence
\end{abstract}

Key words - Occupational Therapy, Social Representation, Pulmonary Tuberculosis, AIDS

\title{
INTRODUCCIÓN
}

La tuberculosis (TB) y el Síndrome de Inmunodeficiencia Adquirida (SIDA) tuvieron el estudio de sus representaciones circunscritas en los contextos históricos en los cuales ambas eran consideradas enfermedades trasmisibles e incurables. La TB, en las décadas finales del siglo XIX hasta los años de 1920 y en el caso del SIDA, a partir de su identificación como nuevo mal, por vuelta del inicio de la década de 1980 hasta 1996, cuando se pasó a conocer y administrar un nuevo tipo de tratamiento (cóctel), que permitió afirmar-la expresión/percepción, vivir con SIDA ${ }^{1}$.

La tuberculosis y el SIDA siguen matando alarmantemente en el mundo de hoy, Por lo mismo, con todos los estudios desarrollados, estas enfermedades causan el temor de la muerte de su titular, ya que están representadas en el imaginario colectivo y expresan el prejuicio cultural de ser portador de la TB o SIDA. Estas enfermedades que presentan un fuerte prejuicio o estigma social, con diferentes matices culturales según la sociedad de que se trate. La conducta reportada más frecuente en los distintos países es tratar de ocultar la enfermedad, lo que también incide en el diagnóstico y tratamiento ${ }^{2}$.

Estigma significa marca, señal en el cuerpo, desdoro, afrenta, lesión orgánica o funcional que indica enfermedad constitucional o hereditaria ${ }^{3}$. Condicionado socialmente, el prejuicio sentido por los enfermos es una dimensión negativa añadida a los malestares propios de la enfermedad, que inciden en su calidad de vida incluso hasta mucho después que esta desaparece. Una de las características del prejuicio, que en el caso de la tuberculosis tiene una historia de siglos de reforzamiento social, es que su componente cognoscitivo (estereotipo) está constituido por una información incompleta y demasiado generalizada y su componente afectivo está asociado a elementos de rechazo muy arraigados que a su vez constituyen una barrera a nuevos conocimientos. 
Así, los portadores de el TB y SIDA, son discriminados, pues sus portadores son relacionados a la lujuria y al desreglamento físico, sexual y moral, que traen consecuencias terribles para ellos mismos y para la sociedad, una vez que tales pecadores se transformaban en portadores de la muerte, debiendo ser temidos y alejados de la convivencia mayor y que son difíciles de ser cambiados ${ }^{4}$.

El cuidado humano prioriza la paz (visualizada como estado de conciencia), la libertad (capacidad de pensar, de imaginar, de soñar y de vislumbrar posibilidades), el respeto (ética), el amor (cuidado), entre otros aspectos. Roach ${ }^{5}$ llama la atención sobre el hecho de la necesidad de atención hoy en día. Para la autora, el cuidado debe ser visto sobre perspectiva ontológica, siendo esencial para nuestro desarrollo y nuestra realización como seres humanos. Además de la habilidad del profesional de la salud para ejercitar y expresar este cuidado, debe considerarse la influencia de su formación académica siendo determinante en la calidad del cuidar que será manifestada profesionalmente.

Heidegger ${ }^{6}$ nos dice que cuidar es lo que unifica la realidad y la posibilidad de constituirse en las dimensiones que van desde las relaciones de cuidado a las de no cuidado. Caracteriza la relación del ser con los otros, significando reciprocidad e indicando potencialidades y posibilidades. Para el filósofo, el cuidar significa solicitud, preocupación con y estar con. Así, el cuidar se revela y se coloca en evidencia a partir de la relación del ser. El filósofo distingue el cuidado auténtico, como una forma de cuidado en que el ser es ayudado a cuidar de si, favoreciendo su potencialidad existencial de venir a ser.

El estudio de las representaciones sociales (RS) ofrece un contexto para el análisis y la interpretación, lo que permite comprender la interacción entre universo e individuo y las condiciones sociales en que interactúan los actores sociales. Permite, también, comprender los procesos que intervienen en la adaptación socio-cognitiva a la realidad cotidiana de las personas y a su entorno social e ideológico. La RS es la herramienta para comprender el sistema de atención y promoción de la salud del portador de la tuberculosis, y SIDA y se basa en la necesidad de recuperar el plano simbólico de las prácticas de los actores sociales involucrados con el objeto de estudio y en la necesidad de identificar los caminos del conflicto entre la población, los servicios de salud y los profesionales. La elección de este concepto como una guía para el análisis de la simbología de las enfermedades se basa, también, en la hipótesis de la existencia de conflictos y relaciones complementares entre conocimiento y sentido común y entre conocimientos técnicos y ciencia producida. Esos conflictos se derivan de una situación de tensión permanente entre las representaciones y prácticas ${ }^{7}$.

La TO posee varios requisitos que la distinguen y la caracterizan como una profesión en la cual el concepto de cuidado incluye todos los atributos que la torna una materia humana, pues la capacidad de cuidar es expresada en determinados momentos por alguien por medio de comportamientos concretos y del hacer artístico. El cuidar en la TO consiste en una forma de conocer, de percibir, de criar y de proyectar sus conflictos en las obras que se construyen. De esa forma, este cuidar envuelve intuición, sensibilidad, creatividad y afecto ${ }^{8 .}$

El arte-actividad es la unión de la TO con el arte para promover la salud. Tiene por objeto mejorar la vida cotidiana de los pacientes por medio de la producción subjetiva, aumentar la calidad de vida y facilitar la adhesión al tratamiento. La práctica artística puede ayudar en la 
promoción del crecimiento personal, en la libre expresión y la actividad colectiva, generando nuevas formas de sociabilidad y contribuyendo con la construcción cultural de la ciudadanía mediante el fomento de la inclusión sociocultural.

Fundamentados en la propuesta de Representatividad Social, podemos aventurarnos a investigar las profundidades del inconciente del paciente cuando buscamos la representación de los signos expresados por los enfermos. De esta forma, la arte-actividad más que traducir el deseo, provoca que la creación se constituya en un lenguaje perfecto, porque su forma es universal por excelencia y su contenido busca y atiende a las necesidades de los sujetos, independientemente de cualquier factor cultural, político, filosófico o religioso.

Para crear es una actividad a partir de la cual se reproduce constantemente la vida. Para Nietzsche ${ }^{9}$, el acto de crear no es un simple hacer práctico que se refiere al terreno de la utilidad, no designa apenas un acto particular y si un acto fuera del cual nada existe. Crear es una actividad constante e ininterrupta y está siempre posibilitando nuevas opciones de vida.

La actividad creadora es la manifestación exclusiva del ser humano, pues solo este tiene la capacidad de crear algo nuevo a partir de lo que ya existe y por medio de técnicas expresivas ${ }^{(10)}$. Ella constituye un ventajoso recurso terapéutico, al propiciar la comprensión de los significados emocionales contenidos en el símbolo, principalmente, en los momentos en que los procesos verbales son incapaces de expresarse

Creemos que el arte puede utilizarse para revelar, en el portador de tuberculosis o SIDA, el significado de su enfermedad y reconocer sus dimensiones, siendo muy importante para el tratamiento. Escapando, así, de la óptica biomédica, que manifiesta especial hincapié en los procesos biológicos de la enfermedad y la cura. Las personas necesitan que las acompañen y las entiendan, porque las complicaciones que conlleva estas patologías pueden invalidarlas en un momento determinado. Entonces, el apoyo que se entrega es agradecido y vital, donde el arte surge como uno medio de revelar el nivel de conocimiento y/o el grado de desarrollo alcanzado en un campo dado, con énfasis en la producción científica reciente, pero sin olvidar la importancia de su construcción histórica y social. Por lo tanto, tenemos como objeto de estudio investigar las representaciones de la salud-enfermedad para los pacientes con tuberculosis o SIDA del Programa de Control de la Tuberculosis Hospital (PCTH), a través de talleres de creatividad, porque a través de la reflexión que se orienta hacia la necesidad de interpretar un universo simbólico que al ser compartido por las personas, posibilita su acción e interrelación en el cotidiano, sirve de soporte para las ideologías dominantes y facilita la institucionalización de prácticas sociales.

\section{TRAYECTORIA METODOLÓGICA}

La relación entre el método cualitativo y el cuantitativo no puede ser pensada en términos de oposición contradictoria. Porque "las relaciones sociales pueden ser analizadas en sus aspectos más 'ecológicos' y 'concretos' y profundizadas en sus significados más esenciales. Así, el estudio cuantitativo puede generar temas para ser profundizados cualitativamente y viceversa"(11).

Entonces, como se trata de producir conocimiento, queda justificada la utilización complementaria de los métodos y técnicas que en ambos abordajes se han generado ${ }^{(12)}$. En el 
caso de esta investigación, se produjo un doble movimiento cuanti-cualitativo, dirigido, en primer lugar, a aportar datos, indicadores y regularidades observables en las nociones y creencias, actitudes y comportamientos en torno a la Tuberculosis o SIDA y, en segundo lugar, a profundizar en la complejidad del fenómeno. En el primer caso se trataba de un estudio extensivo, en el segundo de uno intensivo.

Para investigar los significados latentes de la enfermedad y del tratamiento en pacientes portadores de TB o SIDA, optamos por la utilización de la investigación cualitativa que, para Martins y Bicudo ${ }^{13}$ representa una comprensión particular, con foco centralizado en lo específico, lo individual y en la busca de la comprensión de los fenómenos estudiados. Esta investigación trabaja con el universo de significados, aspiraciones y actitudes que, por su vez, corresponden a un espacio mas profundo de las relaciones, de los procesos y fenómenos, que no pueden ser reducidos a la operacionalización de variables ${ }^{14}$.

Este estudio fue realizado con un grupo de personas del Programa de Control de Tuberculosis Hospitalar (PCTH) del Hospital Universitario Clementino Fraga Filho de la Universidad Federal de Rio de Janeiro (HUCFF/UFRJ) de octubre a diciembre de 2005. Contamos con la participación de 10 portadores de TB o SIDA, 2 representantes del sexo masculino y 8 del femenino, mayores de 18 años. No hubo distinción de raza, creencia, profesión y escolaridad. Fueron excluidos todos los pacientes que tenían otra enfermedad diferente de las descritas anteriormente, así como los que no quisieron participar en los Talleres de Creatividad y los que todavía no tenían diagnóstico o no habían iniciado el tratamiento.

Este trabajo fue aprobado por el Comité de Ética en Investigación Humana y la investigadora consultó a los participantes (personas del PCTH) sobre el deseo de participar del mismo y, después de haber consentido, (Parecer 087/05) firmaron el Término de Consentimiento Libre y Claro (TCLC), conforme las normas de investigación con seres humanos - Resolución no. 196/96. Se proporcionan a los participantes de este estudio que su anonimato será garantizado por un nombre de fantasía, con el fin de proteger su identidad y que los datos recogidos se publicarán en revistas científicas y científicos .

La técnica de la encuesta fue utilizada para describir la regularidad - más en la superficie - en torno de lo que saben y piensan las personas de su afección. Optamos por la estrategia de producir datos por medio de actividades artísticas de pegamento, pintura, dibujo, producción de jabón y velas, los cuales permitieron desencadenar las creencias y los valores de los enfermos sobre su enfermedad. Así, el hacer artístico integrado al símbolo, posibilitó al paciente, en el momento de la elaboración de su obra, tener un espacio destinado a expresar, por medio del lenguaje artístico y simbólico, sus conflictos y angustias en relación a su enfermedad, lo que favoreció el aprehender elementos anclados más profundamente en la subjetividad de las personas, en que tiene que ver con que sienten y hacen frente su afección. Se diseñaron así dos instrumentos de naturaleza distinta: la entrevista a profundidad y talleres de creatividad

La recopilación de datos empezó por el dibujo y luego la expresión verbal del significado de la creación. Todas las expresiones verbales fueron grabadas y transcritas. El análisis cualitativo de los datos recogidos se divide en cuatro etapas a partir de la transcripción de los relatos, registrados. La primera fase del estudio se organizó y ordenaron los relatos, a partir de la revisión de la transcripción y comparación con la grabación y codificación de los documentos. En 
la segunda fase se produjo la clarificación del Corpus del relato a través del establecimiento del perfil biográfico y del léxico-repertorio de cada uno de los entrevistados. Para esto último se afinaron los campos semánticos (categorización). En la tercera fase se integraron los sinónimos y expresiones utilizados por los entrevistados y que aparecen en la ficha individual. En la cuarta fase se realizó el inventario de significaciones, es decir, se organizaron los significados en categorías, mediante la utilización de la llamada "rejilla de análisis".

Las representaciones sociales se conciben como una construcción mental de un objeto, un conjunto organizado de información, conocimientos, ideas e atributos de ese objeto. Están incluidos en la representación, también, los sentimientos que acompañan a la adquisición de conciencia de las propiedades del objeto, ya sea del objeto global o de algunos de sus rasgos o propiedades $^{15}$.

Las representaciones sociales son definidas como maneras específicas de entender y comunicar la realidad e influyen a las personas a través de sus interacciones. Estas formas de pensar y crear la realidad social están constituidas por elementos de carácter simbólico, ya que no son sólo formas de adquirir y reproducir el conocimiento, sino que tienen la capacidad de dotar de sentido a la realidad social. Las representaciones sociales no son sólo productos mentales, son construcciones simbólicas que se crean y recrean en el curso de las interacciones sociales. No tienen un carácter estático, ni determinan inexorablemente las representaciones individuales. Siendo que las representaciones son figuraciones mentales aprendidas por vía de la socialización - introduce valores y reglas de conducta -, cada sociedad selecciona los atributos que constituirán el concepto de normalidad, y, por oposición, define la noción de desvío. Así, cualquier elemento que no coincida con las definiciones culturalmente postuladas, se convierte en un peligro. Tal es el caso de algunas enfermedades como la tuberculosis o SIDA, en su visión estereotipada, causa deformidades en el cuerpo; porque, siendo éste una representación de la sociedad, no sólo como proceso exclusivamente biológico, sus significantes en el plano fisiológico vienen a representar fenómenos sociológicos ${ }^{16}$, que tienen como finalidad transformar lo desconocido en algo familiar.

Moscovic ${ }^{17}$ desarrolló este método que puede, también, ser indicado para el estudio de ciertos temas de representaciones, donde la dimensión no verbal es esencial. Por tanto, en las investigaciones que utilizan esta técnica, la argumentación es identificada en tres fases: la producción de un dibujo, la verbalización de los individuos con base en estos dibujos y el análisis (cuantificable) de los elementos que constituyen la producción gráfica. De esta manera, la representación, posibilita el acceso más fácil a su contenido y al conflicto interno producido y expresado en la representación. Los dibujos permiten captar el contenido y formular hipótesis sobre los núcleos centrales de la representación, considerando que, en la mayoría de las veces, no son sobre posición de elementos, y si conjuntos estructurados y organizados de elementos alrededor de significados centrales. Así en el caso de la Terapia Ocupacional, los prejuicios pueden desaparecer a medida que se va cayendo en la cuenta de su intencionalidad, entonces aumentará la voluntad de la persona con TB o SIDA de conocer y comprender su enfermedad. En el caso de los dibujos, la aproximación es casi siempre voluntaria, intuitiva y la mejor manera de hacerlo es a través de una percepción racional e intelectiva.

Las representaciones se estructuran alrededor de tres componentes fundamentales: la actitud hacia el objeto, la información sobre ese objeto y un campo de representación donde se organizan 
jerárquicamente una serie de contenidos. Existen dos procesos a través de los cuales se generan las representaciones sociales: anclaje y objetivación. El primero supone un proceso de categorización a través del cual clasificamos y damos un nombre a las cosas y a las personas. Este proceso permite transformar lo desconocido en un sistema de categorías que nos es propio. El segundo proceso consiste en transformar entidades abstractas en algo concreto y material, productos del pensamiento en realidades físicas y conceptos en imágenes ${ }^{17}$. Ambos procesos son receptores y su actitud debe ser necesariamente activa ya que su esfuerzo dirigirá a participar en un bienestar de los portadores de TB o SIDA. En ambos casos es indispensable la comprensión del mensaje, supondrá un esfuerzo individual de elaboración; como terapeutas ocupacionales no podemos olvidar nuestro papel el esta relación humana, juegan la intuición y la empata.

La objetivación, es el proceso a través del cual producimos imágenes concretas, que nos permiten comprender mejor lo que se quiere decir. Consiste en transferir algo que está en la mente en algo que existe en el mundo físico, en transformar la relatividad del conocimiento científico en la imagen de una cosa, en reducir, en definitiva, la distancia entre los conceptos científicos y la expresión de lo real ${ }^{18 .}$ Este mecanismo se encuentra bajo la influencia de la inserción de los sujetos en la sociedad y en sus condiciones sociales. Se realiza a través de tres fases: la construcción selectiva, la esquematización estructurante y la naturalización. Así, la objetivación está notablemente relacionada con una serie de condiciones sociales, que influencian la inserción de las personas en la estructura social. En el caso de la TB o SIDA se el estigma caracteriza por el ocultamiento en sus dos acepciones (enmascaramiento y encubrimiento), al respecto se tiene que es a la familia, a los amigos, a los compañeros de trabajo y a los jefes a quienes los pacientes tienden a ocultar, no sólo el nombre, sino la afección misma.

Moscovic ${ }^{17}$ se refiere al anclaje como el mecanismo que permite al individuo familiarizarse con objetos que hasta el momento le eran desconocidos. Usamos las categorías que ya son conocidas para interpretar y dar sentido a los nuevos objetos que aparecen en el ámbito social. Para nosotros, el proceso de anclaje al pensamiento se integra a una nueva información sobre un objeto, que aparece con un significado específico. Este proceso se manifiesta por la asimilación y acomodación del objeto, porque las informaciones recibidas son alteradas por nuevos esquemas de intercambio de informaciones. Se puede decir, entonces, que este proceso se refiere al enrizamiento de la representación social y de su objeto. El proceso de fijación articula las tres funciones básicas de la representación: integración de la función cognitiva de la novedad; la función interpretativa de la realidad y la función de orientación de la conducta y las relaciones sociales. En los portadores de TB o SIDA la expresión evoca, sin lugar a dudas, a un tipo de enfermo en particular, a aquel a quien la enfermedad le ocasiona lesiones corporales que hacen evidente el padecimiento El predominio de esta imagen en el propio afectado es revelador de que éste tiende a reducir su representación social a una categoría de sujetos, que ancestralmente se ha configurado como la portadora del estigma.

Tanto el anclaje como la objetivación hacen familiar lo desconocido. El primero, transfiriéndolo a nuestra esfera particular, donde somos capaces de compararlo e interpretarlo. El segundo, reproduciéndolo entre las cosas que podemos tocar y en consecuencia, controlar. Teniendo en cuenta la opinión de Moscovici ${ }^{17}$, las representaciones sociales se fundamentan en el conocimiento del sentido común, de forma flexible, y ocupan una posición intermedia entre el concepto que se tiene del sentido de la realidad y la imagen que la persona envió. 
El discurso no es sólo una expresión directa de las representaciones de los temas, es, también, una construcción hecha por un análisis cuidadoso, ya que el mundo semántico de los elementos producidos está influenciado por los aspectos cognitivo, emocional y simbólico, que tienen sentido en el pensamiento. No debemos olvidar un importante precepto teórico planteado por esta teoría, que establece que toda representación es siempre una cosa (el objeto) y alguien (el sujeto, la población o el grupo social). Considerando la relación dialéctica que debe existir entre ellos, se debe elaborar un análisis lógico, que no es una secuencia lineal de dirección, sino un proceso dialéctico que se mueve a través de contradicciones ${ }^{19}$.

En el contexto de la TO, las modalidades de expresión no verbales tienen gran importancia en la relación terapeuta-paciente, una vez que el objeto creado revela señales de esta comunicación. Estas modalidades se manifiestan por medio de signos paralinguísticos del cuerpo, expresadas en el mirar, la entonación, el cuerpo en movimiento e en las expresiones emocionales faciales. En relación a la actividad-terapeuta, existe la capacidad para comprender problemas de rendimiento en el motor-sensorial (la praxis, la coordinación motora, percepción y habilidades), los componentes de la ordenación integrada de cognitivas (memoria, atención y concentración), los aspectos psicosociales (valores, intereses, funciones y relaciones) y los aspectos sociales y profesionales (auto cuidado, trabajo y ocio).

Pensamos que sería posible incluir estudios con dinámica de creatividad (metodologías aplicadas a la práctica de TO). Con este objetivo buscamos autores que tuvieran afinidad con esas dinámicas cognitivas a partir de la Referencia de las Representaciones Sociales. Destacamos que Talleres de Creatividad son el medio mas fácil de producir datos y conocimientos. De esta forma, optamos por el proceso de proyección de las ideas y acciones, a partir del arte, que mostraron lo que inconscientemente los portadores del tuberculosis y o SIDA pensar acerca de su enfermedad y tratamiento ${ }^{20 .}$.

Los Talleres de creatividad comenzaron con actividades artesanales desarrolladas por personas con tuberculosis o SIDA. Concluidas estas actividades, ellos respondieron a la pregunta fundamental de este estudio: ¿que representa para usted su enfermedad? Así, le dieron sentido a sus trabajos sobre la base de su construcción mental, su situación social, sus creencias y valores. Creemos que a través de las técnicas artísticas de verbalización en profundidad, sus creaciones y asociaciones de palabras pueden tener acceso a sus contenidos inconcientes, lo que, por naturaleza, estimula la espontaneidad y la aceptación de la enfermedad. La representación social es una categoría que pretende capturar el conocimiento cotidiano, revalorízalo, reivindicar lo que llamaríamos “el sentido común”, a través de la sustitución de un concepto (abstracción) por una imagen, idea o noción compartida (objetivación), se hace fácilmente comprendida por los otros. Ante una fisura de la cultura, la sociedad produce una imagen, o una representación para poder sostenerse. Es un modo de mantener el sentido social y por ello, se arma una interpretación de la realidad.

Las imágenes son sensaciones mentales, impresiones que los objetos y las personas dejan en el cerebro. Lo que caracteriza la imagen es, antes de todo, el reflejo, la selección de la información y la interdependencia. Si la imagen parte del objeto, la percepción se concentra en el individuo, conduciéndolo a un papel activo, sea utilizando su experiencia vivida o como proyección del individuo en el objeto ${ }^{17 .}$ 
La importancia, la magnitud y la complejidad de la representación del fenómeno posibilitan combinar los enfoques creativos y las perspectivas teóricas que se han articulado de manera complementar. A partir de este momento se puede encontrar el cuerpo de las ideas, actitudes, valores y conocimientos producidos por los pacientes con tuberculosis.

En la búsqueda de construir el espacio tiempo que posibilite el conocimiento concretizado por este grupo de investigación elaboramos la siguiente cuestión: ¿como usted representaría su enfermedad? A partir de este tema, los pacientes pasaron a realizar dibujos y pegamentos, así como a fabricar velas y jabones.

\section{RESULTADOS Y DISCUSION}

El papel de la TO con los portadores del tuberculosis y o SIDA, en los talleres de creatividad, basándose en la voluntad y el deseo de la persona. Este desarrollo no es un puro y simple proceso de acumulación, sino un proceso dinámico de cambio, que se produce en los planos físico, clínico y, fundamentalmente, psicológico. Los pacientes fueron liberando, poco a poco, el mundo de la enfermedad, los prejuicios y la discriminación de determinismo biológico. A partir de ahora, surgen posibilidades de nuevos hábitos, idoneidad y destrezas importantes para la vida.

Considerando la estructura teórica que fundamenta los talleres de creatividad, creemos que el papel de la TO, en personas con tuberculosis o SIDA, sea una obra de construcción de sentido a través de acciones concretas en el mundo, que proporcionan a estas personas el crecimiento y la independencia. Estos talleres no son suficientes para desarrollar la habilidad; es necesario, también, un pensamiento flexible, a fin de utilizar esta capacidad como una herramienta para la transformación y la comprensión del mundo.

Cuando se habla de prevención, las políticas de salud pública, la base de referencia es el modelo de la clínica centrado en la técnica de transmisión de información fundamentalmente para cambiar el comportamiento. En el presente trabajo, implementamos una nueva óptica de ver las formas de prevención, haciendo hincapié en los aspectos culturales, económicos, políticos, emocionales y éticos, donde el comportamiento humano está implícito, especialmente en situaciones de vulnerabilidad social.

Este estudio se fundamenta en datos empíricos sobre la importancia de la enfermedad y el tratamiento de pacientes con SIDA o tuberculosis, producidos en Talleres de Creatividad. Es utilizada la representación social como un medio de obtener conocimientos sobre el cuidado de estos pacientes y para interpretar la realidad en torno a cada paciente. Hemos observado que, después de conocer el diagnóstico, estos pacientes expresan un sistema de pre-decodificación de la realidad, determinado por el número de anticipaciones, expectativas y preocupaciones de entender esta enfermedad y su tratamiento.

Desarrollamos esta investigación, por medio del hacer artístico, a partir del proceso evolutivo de la conciencia, consideramos que existen las condiciones propicias para que se aproveche esa posibilidad de diálogo y crítica reflexiva en torno de lo que significa el dibujo y, para un crecimiento mutuo y compartido. Esta situación, de manera particular se evidenciaba por el 
solidez en lo relacionado con la utilización de el referencial artístico que sustentara los trabajos realizados y limitando su producción al contraste con experiencias culturales, locales y sociales.

La ejecución de las actividad de expresión a favor de la proyección de los símbolos (energía síquica) y el conocimiento de sí mismo. De esta manera, el arte posibilitó la expresión del self y del contenido personal, implícito en cada creación y explícito en el resultado final, lo que favorece la manifestación de conflictos internos (estar con TB o SIDA) y posibilita la catarsis emocional de forma directa y no intencional (adhesión al tratamiento).

El trabajo utilizado describe los resultados obtenidos a partir de la intervención con la TO, que tiene un aspecto natural en la conciencia y la reflexión sobre el cuidado del paciente. Además, incluye la persistente preocupación de utilizar actividades que tengan relación con la realidad de cada uno, haciendo posible los cambios en la conciencia y el comportamiento y la existencia de redes de apoyo que contribuyan con la transformación de las condiciones sociales a que están sujetos los portadores de tuberculosis o SIDA.

En esta investigación, los pacientes, a partir de representaciones para dar significado a las imágenes producidas, permitieron a los investigadores deducir, en las verbalizaciones de sus ideas, pensamientos y expresiones de las emociones y los sentimientos acerca de su enfermedad y proceso de tratamiento. Buscamos resaltar en las palabras (sistema de vivir, actuar, reaccionar y transformar el propio ambiente donde se vive y con quien se vive) y en las imágenes sus proyecciones inconcientes.

Al entrar en contacto con los diversos tipos de imágenes concretizadas por los pacientes, los tornamos conscientes de sus mensajes y, automáticamente, los reaproximamos del origen de sus propias conciencias (inconsciente colectivo). A partir del momento en que los sujetos dieron vida a los objetos, se permitieron salir de la oscuridad y del no saber (enfermedad) para conquistar la libertad de escoger (adhesión o abandono).

Fundamentándonos en las evocaciones de los pacientes, percibimos que cuestiones como sentimiento, preconcepto, exclusión y muerte son sentidas después de la confirmación de la enfermedad, de la misma manera, que las verbalizaciones están relacionadas con las acciones, expresiones, concepciones y consecuencias de la enfermedad. En ese ejercicio, estábamos atentos en los intereses de esta investigación, considerando el consenso y la interacción de la mayoría, así como el proceso de organización, donde es relevante que las búsquedas por la cultura y el conocimiento consensual no sean separadas ${ }^{21}$.

\section{LOS ENFRENTAMIENTOS FÍSICOS, EMOCIONALES Y SOCIALES.}

Percibimos que los pacientes enfrentan la bipolaridad entre tomar los medicamentos específicos o parar con los mismos y, así, desistir del tratamiento. Los pacientes comentan que en la mayoría de las veces, es muy difícil soportar reacciones corporales (malestar, falta de aire, mareo, etc.) derivados de la exigencia de ingerir las drogas. En ese sentido dice Adilson: 
Fue entonces cuando descubrí la enfermedad. Había perdido peso, llegué a $48 \mathrm{~kg}$. Apareció alrededor de cinco piedras en la frente del cuerpo y no podía descubrir lo que había, y luego vine aquí para... descubrir la tuberculosis.

Los pacientes no son siempre capaces de relatar a los médicos el sufrimiento por el cual pasan. Otras veces, ni son oídos por los médicos, pues lo que se pide es que aguanten firmemente el tratamiento (Adilson). Percibimos que el estado de ánimo disminuye cuando aparecen limitaciones físicas como consecuencia de la evolución de la enfermedad en el organismo. Así, la persona se torna apática y muchas veces sin condiciones de reaccionar positivamente, entregándose al desánimo. Este estado altera su naturalidad, genera dependencia de los parientes y coloca en un segundo plano las actividades realizadas en el pasado, considerando que el paciente se encuentra dependiente de su disposición física, del preconcepto y de su condición afectiva y mental para soportar su realidad. Veamos, a seguir, el relato de Alberto:

Yo jugaba fútbol pero yo no conseguía correr más de 10 minutos, ahí paraba y me quedaba en el sol caliente. Esperaba enfriar un poco mi cuerpo para poder correr de nuevo. Cuando comenzaba a toser, todos mis colegas se apartaban y decían que yo iba a morir. Yo me quedaba chocado, pues ellos tenían miedo de contagiarse con la enfermedad. Ellos decían: eso ahí se pega, no voy a quedarme cerca de ti, Alberto.

Se observó que el prejuicio y la discriminación se producen dentro de la familia y de los amigos. Alberto dice que aun necesita mucha fuerza para soportar la pérdida, la desintegración de la familia y de los amigos y ni consigue llevar a cabo sus actividades de rutina por él estar debilitado.

Al realizar la escucha sensible, como sugiere Barbier ${ }^{22}$, podemos auxiliar a estos pacientes en la verbalización de todas sus angustias y ansiedades, porque se evidencia la elaboración afectiva del sentimiento o de la emoción que de ellos se apodera, interfiriendo en el desempeño social subsiguiente, que surge como preocupación marcada por el estigma y por el miedo del contagio o de la autocondenación. Márcio ejemplifica cuando dice:

Mi opresión está relacionada con el miedo, el temor de la propia enfermedad, el miedo de las personas, el miedo del contacto con ellas porque nos mandan a alejarnos, entonces la gente, sin intención de ofender, ofende... Nos preocupa no solo transmitir el virus a la gente, también nuestro cambio...

Percibimos que el sentido de la enfermedad pasa por la dinámica del vivir, se procesa en las relaciones del hombre con la naturaleza y la sociedad y engendra subjetividades dentro y fuera del ambiente en que el paciente vive, trabaja, se cuida y se relaciona. Observamos, a seguir, como Marcio conceptúa enfermedad y salud:

Enfermedad es la basura que las personas votan sin cuidado, es lo sucio, la inmundicia y la falta de educación. La salud es el cuidar de las personas, de los árboles y de la vida. 
La profundidad de las nociones y creencias que fueron reveladas por la existencia de un elevado nivel de encubrimiento y enmascaramiento. Los enfermos, por el temor al rechazo, ocultan su afección la mayoría de las veces y cualquiera sea la circunstancia. Hay que asumir que la necesidad de encubrir retrae a los individuos, generándoles problemas para su integración en los diferentes planos de la vida social y de la familiar. Cuando podría ser explicado de que, logrando ocultar su afección, no tienen porque aislarse o esconderse de los otros considerados normales. Encubriendo y enmascarando se protegen del rechazo. De todas las maneras, habría que enfatizar la inconsistencia de las respuestas al respecto, tal vez derivada de la resistencia a aceptar la autoexclusión. Así ficha evidenciando una significativa tendencia a la autoidentiticación negativa, que constituye un mecanismo fundamental de la estigmatización. En la medida en que el estereotipo corresponde a un individuo desacreditado, el paciente percibirá mayores barreras, inhabilitándose para llevar una vida social y familiar armónica.

Marcos nos ejemplifica el estigma al decirnos que no habla de la enfermedad ni con sus familiares: ...

Por causa del preconcepto, porque las personas creen que van contagiarse con la enfermedad, van querer separar los vasos y todo. Como ya vi a otros haciendo eso, yo prefiero no contar.

Sandoval, se refiere a la falta de respeto que está presente en el hospital, inclusive entre los profesionales de la salud. Podemos ver en su discurso:

Al llegar al segundo piso yo cogía la receta médica y si estaba vació entraba para ser atendido. Cuando llegaba allá la muchacha me preguntaba: ¿trajo la máscara? La cara de ella era medio extraña. Yo creo que ella tenía miedo. En momentos como eses, el paciente se enoja y abandona el tratamiento... La enfermera tiene miedo de contraer la tuberculosis, creo que no era necesario utilizar la máscara.

Podemos percibir en las expresiones de estos pacientes que las causas de las alteraciones emocionales mezclan elementos de orden subjetiva (preconcepto), de orden colectiva (contagio) y de orden natural (falta de orientación del Ministerio de Salud). Marcelo expresa bien estas representaciones... Yo observo mucho, la verdad es que el Ministerio de Salud está sin control (TB y SIDA). ... La enfermedad es una forma de abandono... un abandono social...

Esta categoría, cargada de dolor y emoción, dolor y sentimiento, dolor y pasión, dolor y justificaciones, nos hace reflexionar que el estigma es desencadenador de sentimientos y fenómenos imprevistos, que nos colocan diversas cuestiones, como: ¿por qué los portadores de TB o SIDA se dejan agredir por la sociedad y por eso se excluyen voluntariamente de ella?; ¿por qué continúan viviendo con sus compañeros, en la propia casa o en la misma comunidad cuando son agredidos verbalmente o por actitudes como las de separar utensilios y de no se enfoque? y ¿que les impide abandonar los familiares? Veamos por el relato de Mauricio, que mismo en condiciones materiales y afecto ello muestra una estratégica de afrontamiento frente a esta RS negativa de su enfermedad: 
En mi casa solo mi esposa sabe que yo tengo TB, mas nadie, ni mi papá, ni mi mamá, ni mismo mis hijos y nunca van saber, porque las personas comentan y otras hasta se apartan de mi.

Para Barbier es preciso que cada un de nosotros sepa interpretar lo que el otro dice, pues el otro es nuestro espejo, un espejo activo que entra en conflicto con nosotros mismos, para que descubramos, en las relaciones humanas, a que no debemos temer en el confronto de nuestros valores esenciales. Por tanto, el dolor del cuerpo asociase al dolor moral. Sin establecer preponderancias de uno sobre el otro, esos dolores son sentidos y relatados por todos los entrevistados y proyectados en sus creaciones. De esa manera, en sus representaciones, los sentimientos sobre la enfermedad sentida son extremamente fuertes y traen para nuestra reflexión sensaciones y emociones que necesitan ser pensadas. Sentir es la cuestión fundamental de esos pacientes cuyas sensibilidades y sensaciones sobre la violencia del preconcepto causan miedo y llevan al aislamiento. Podemos ver en las palabras de Adilson:

No salía del cuarto, no conversaba bien con las personas, no jugaba con los niños. Todo separado. Dejé varias cosas que yo hacía, dejé de salir. Después que yo me enfermé, yo dejé todo eso. No hago ciertos tipos de actividades.

Barbier nos dice que no es tanto la representación del peligro que provoca la emoción y si la representación del cuerpo, pues nos emocionamos con la violencia real y entonces verbalizamos el sentimiento profundo. Concuerdo con Oliveira ${ }^{(23)}$ cuando dice que es necesario avanzar de una valorización de la dimensión biológica y humana para una valorización de la dimensión síquicaemocional y social. Percibimos que para los portadores de TB o SIDA es mas difícil aceptar una agresión verbal que una física. Silvia ejemplifica bien la representación del peligro cuando verbaliza:

...Si las personas de la comunidad supieran que yo estoy con TB, me escupirían hasta en la cara. ¿Como? Los hijos de ellos son unos mari guaneros desgraciados: beben, fuman, huelen, y eso para ellos es normal, pero una persona con esta enfermedad no...

\section{ENFRENTAMIENTO A LA MUERTE}

Podemos verificar que los portadores de TB o SIDA pasan por varias etapas en el transcurso del prolongado tratamiento. Ellos representan a su finitud por la negación, por el aislamiento (mecanismos temporarios de defensas del ego) y por el dolor psíquico frente al diagnóstico. Muchos verbalizan la muerte y el morir por la descubierta de la enfermedad y por las reacciones adversas a los medicamentos. En ese sentido Alberto dice:

...Ahora estoy con un problema en el hígado y en el corazón. (Después que tomé choque en el corazón, porque mi corazón paró el pericardio, era pericardie, yo creo...). En el comienzo, cuando yo supe que estaba con 
SIDA, yo no quería aceptar, quería huir del hospital, quería matarme. Querían llevarme al psicólogo...

En este instante el ambiente le es hostil y el sujeto proyecta sentimientos de revuelta y resentimiento. Es el momento en que los síntomas ya no son tan aparentes y él abandona el tratamiento como medio de fuga de si mismo y de la responsabilidad de tratarse. En esta fase, el dolor surge de forma agresiva o por medio de la revuelta y del cuestionamiento: ¿por qué conmigo? Sandoval expresa y verbaliza:

Por cualquier cosa yo tenía que usar la máscara y ahí nunca más yo vine. Es una cosa de esas que a veces hasta desanima a las personas. Vine a hacer el tratamiento. De la manera que las personas son tratadas, porque las personas tienen miedo, miedo de pegar la enfermedad. Ahí, en una de esas horas, la persona se irrita y abandona hasta el tratamiento.

Después de superar la rabia, el paciente se encuentra mas tranquilo y reflexivo. Así pasa a usar los medicamentos buscando ser acepto en el medio y la posibilidad de ser cuidado, pero tiene consciencia de las limitaciones que la enfermedad le trae, como podemos percibir en las palabras de Antonio:

...Tuve problemas: riñón alterado, taquicardia, trombosis venosa, exceso de cosas. Yo estoy con TB y SIDA, yo despierto en la casa, me quedo parado, juego con los niños...Me separé totalmente de los amigos por no poder salir, no poder hacer nada, no poder beber bien, no poder jugar, no poder perder una noche de sueño. Ahí yo prefiero quedarme en la casa, trancado, viendo la televisión...

Iniciase el proceso de depresión en el momento que los pacientes toman conciencia de su debilidad física y comprometimiento social y emocional. A partir de ahí ellos ya no consiguen negar la condición de estar enfermos y de ser vector del contagio. Ellos perciben que su finitud está evidenciada en el aislamiento, en la depresión, en el separar las cosías, en las reacciones adversas y en las pequeñas muertes diarias. En ese sentido, Adilson y Estela expresan:

Mis hermanos me llevaron para el hospital, yo pensaba que iba a morir allá. Pensé que esta vez iba directo para el cajón... A veces, cuando mi hermana hace una sopa para mí y mi sobrina la lleva a mi casa, mi hermana le dice: no se demora no... Una hermana le decía a los otros: cuidado que su hermano va a morir (Adilson).

Yo estaba prácticamente sola... Mi hijo casi no iba a mi casa. Luego, él que es hombre! Es mi hijo ... Si antes ele iba poco, ahora ni siquiera aparece (Estela).

Entender el significado de la enfermedad y lo que implica en la dinámica de la vida, se transforma en la relación humana con la naturaleza y la sociedad y crea subjetividades, dentro y fuera del entorno en el que el paciente vive, trabaja y se relaciona. 


\section{CONSIDERACIONES FINALES}

Cuidar de estos pacientes es estar frente a heridas reales y mentales, presenciando una convivencia con el miedo. No conocemos sus cotidianos, vidas, sueños e dolores. Ellos llegan a nuestra frente muriendo y nos hacen ir a buscar la vida. La perspectiva es asegurar que la valorización de ese enfermo estigmatizado, debilitado y insertado en una realidad socio-histórica cuyas representaciones son reveladoras de su cotidiano, deba ser enfatizada, con vista a la superación de los miedos que tienden a aniquilar este ser. Esa valorización puede comenzar en el cuidado mas humano y personalizado por parte de los servicios de salud.

Los talleres de creatividad se desarrollan por medio de diversas actividades artesanales. En estos locales se trabajan las cuestiones sobre el tratamiento y la integración o reinserción social del paciente. También, se ofrecen a los pacientes experiencias prácticas para sus tratamientos, relación con los equipos de salud y propuestas de formación y desarrollo de habilidades, actitudes y hábitos de trabajo, tales como responsabilidad, comunicación, presentación social, organización del trabajo en equipo, manejo del dinero, etc ${ }^{24}$

Las conversaciones revelan que con la autoestima disminuida hay necesidad de cuidados mayores que aquellos ofrecidos por el servicio de salud. Los pacientes demuestran su fragilidad frente a la expectativa de la enfermedad y el recelo de no recibir la protección y el tratamiento adecuados, llevándolos a la muerte.

Identificamos que la representación encuentra se basada en el concepto de ciudadanía, traducido por el reconocimiento de los derechos personales y de la responsabilidad del Estado, donde el servidor público tiene como función y obligación viabilizar tanto el cuidado específico como el diagnóstico precoz, para que el paciente no permanezca como fuente de contagio.

Los símbolos demuestran que los enfermos pasan por varias categorías: la enfermedad, el preconcepto, la muerte, la vida y el dolor. Sin embargo, la percepción de la inhabilitación social que tiene el enfermo (dimensión subjetiva) contrasta con su capacidad de integración y con la que se le atribuye al portador de TB y o SIDA. Así el describe una persona que puede trabajar y que puede realizar su trabajo con un rendimiento similar al que tenía antes de aparecerla enfermedad. Por otro lado, no sólo se percibe como una persona que no es rechazada por su familia, sino que considera tener una importante proximidad con ella. Tal contraste sin embargo, no debe llevar a perder la perspectiva en relación a la inhabilitación social ya que independientemente de la inexistencia de cambio en la apariencia y de la actitud favorable de algunos a participar activamente en la vida social.

Tal imagen evoca, sin lugar a dudas, a un tipo de TB Y el SIDA, a aquel a quien la enfermedad le ocasiona lesiones corporales que hacen evidente el padecimiento. El predominio de esta imagen en el propio afectado es revelador de que éste tiende a reducir su representación social a una categoría de sujetos - los tuberculosos -, que ancestralmente se ha configurado como el portador del estigma. Tal categoría se identifica con el tipo de estigmatizado llamado por Goffman ${ }^{25}$ el desacreditado. Sin embargo, junto a esa imagen, parece coexistir una más general y menos estigmatizante, donde aparece una persona que tiene una debilidad física. 
Comprendemos que dentro de los factores que el propio enfermo asume como lo que le impide una integración social, se encuentra el temor a ser rechazado por las otras - personas, por los amigos, por la pareja. También es intenso su temor a ser expulsado del trabajo, así como el ser percibido como una persona diferente. Así pues, el temor a ser rechazado o excluido representa para el enfermo el principal y más grave problema que debe enfrentar y resolver para poder desarrollar una vida social, laboral y familiar armoniosa. Otro factor de la inhabilitación es el ocultamiento, que constituye una tendencia generalizada en el paciente, obligándolo o presionándolo a adoptar con frecuencia comportamientos de enmascaramiento y/o encubrimiento. Ello es así por la intensidad de su temor a ser rechazado.

Identificamos que la TB y el SIDA producen un cotidiano de convivencia con la muerte que resulta en una diversidad de significados para los individuos atingidos, que en general están asociados a los altos índices de mortalidad y a las endemias por largos períodos. Pues, tanto la TB como el SIDA, tuvieron un carácter brutal en sus surgimientos y tienen aspectos misteriosos, incomprensibles e inexplicables para el saber médico, dejando perplejos los medios científico y social, asumiendo, así, la dimensión de pandemia. Todo lo que viene de esas enfermedades presenta alta carga simbólica, pues existe el miedo al aniquilamiento físico y moral de los individuos y de la sociedad como un todo.

La comprensión de las condiciones de la enfermedad y su naturaleza compleja, requiere del terapeuta ocupacional el acto de compartir el conocimiento con los clientes en los talleres. Creemos que es necesaria una planificación más sistemática de la salud, considerando prácticas que incluyan la opinión pública en el proceso y aprovechando sus conocimientos para contribuir con la transformación social ${ }^{26}$

Es importante señalar la inconsistencia de las diferencias entre las nociones y creencias de los individuos con incapacidades distintas. Ello confirma nuestra intuición en torno a la homogeneidad de los elementos constitutivos de la representación social del enfermo. En otro plano, el de las actitudes y conductas, se establece, una independencia de éstas y las lesiones que se posean. Esta uniformidad del comportamiento tendría que ver con una representación social que iguala a todos los enfermos; cualquiera sean sus características, todos los portadores de TB y o SIDA, y eso es lo que importa en la situación del tratamiento.

La TO se ha convertido en un camino para la posible liberación de los conflictos internos de las personas, a través de la construcción de alguien que reconoce sus necesidades, sus deseos y sus posibilidades, haciendo uso de la conciencia para actuar y decidir sobre la continuación del tratamiento. La TO tiene un papel primordial en el cuidado de pacientes con tuberculosis o SIDA, que su acción no se limita a la intervención con la persona con incapacidad, sino que se extiende al entorno social a que pertenece esta persona. Pudiendo actuar como una aliada en los procesos de inclusión social, de inclusión en el lugar de trabajo, en los espacios comunitarios, de láser, etc.

Es importante recordar que toda acción en la TO no es realizada de manera abstracta, sino que implica una estructura concreta que permita y apoye la acción. Por lo tanto, el terapeuta ocupacional trabaja para conducir una manifestación de la voluntad de ser y actuar en el mundo. Desarrolla acciones específicas destinadas a la unidad de la acción voluntaria a través de actividades que promueven las situaciones prácticas y simbólicas. Con las técnicas de abordaje se 
puede establecer un proceso terapéutico basado en la relación terapeuta-actividad-portador de tuberculosis y SIDA, donde cada uno de los miembros asume el papel de agente transformador.

El trabajo con la familia siendo parte del proceso terapéutico, para fomentar la construcción de una ayuda a los enfermos, contribuyendo con la aceptación de la enfermedad. El terapeuta es parte del proceso de tratamiento mediante el establecimiento de una relación de confianza que permite el enfoque de la vida cotidiana.

Muchas veces el camino de la cura parece no surgir y la posibilidad más próxima para reducir: la dolor; el sufrimiento, el preconcepto y la muerte es tornar posible la esperanza. Así la TO surge como una posibilidad de auxiliar a los enfermos a reconocen riesgos reales, las situaciones límite, las reacciones del estigma y la certeza de que, a pesar de todo, sobreviven.

\section{AGRADECIMIENTOS}

Agradecemos al Dr. Luis M. G. Reyes por su valiosa contribución en este trabajo.

\section{REFERENCIAS BIBLIOGRÁFICAS}

${ }^{1}$ KRITSKI, AL; CONDE, M C; SOUZA, G M. Tuberculose: do ambulatório a enfermaria. 3. ed. São Paulo: Atheneu, 2005.

2 ÁlvareZ GORDILlO GC, ÁlVAREZ GORDILlO JE, MOLINA ROSALES D. La búsqueda de atención para la tuberculosis en Chiapas, México. Rev Panam Salud Pública: 2001; 9(5):285-91.

${ }^{3}$ HUDELSON P. Gender differentials in tuberculosis:the role of socio-economic and cultural factors. Tubercle Lung Dis: 1996;77:391-400

${ }^{4}$ NASCIMENTO, DR As pestes do século XX: tuberculose e Aids no Brasil, uma história comparada. Rio de Janeiro: Fiocruz, 2005.

${ }^{5}$ ROACH, P..English phonetics and phonology: A practical course. 2nd edition. Cambridge: Cambridge University Press, 1991

${ }^{6}$ HEIDEGGER, M. Conferência e escritos filosóficos. São Paulo: Nova Cultural, 1991.

${ }^{7}$ MOSCOVICI, S . A Representação Social de Psicanálise. Rio de Janeiro: Zahar Editores, 1978

8 TEDESCO, J. C. Paradigmas do Cotidiano: Introdução à Constituição de um Campo de Análise Social. Santa Cruz do Sul: Edunisc,1999. 
${ }^{9}$ NIETZSCHE,F.W. Genealogia da Moral. Trad. Paulo César Souza. São Paulo, Brasiliense, 1988.

${ }^{10}$ VYGOTSKY, L Seminoevicht. La imaginación y el arte en la infancia. Madrid: Akal Editor, 1982.

${ }^{11}$ SANCHES, O. \& MINAYO, M. C. S. Quantitativo-qualitativo: oposição ou complementaridade? Cadernos de Saúde Pública:1993: 9: 239-248.

${ }^{12}$ ROMERO-SALAZAR, A., 1990. Diversidad o especificidad del análisis sociológico. Revista Contextos . 1990: 40-43.

${ }^{13}$ MARTINS, J.; BICUDO, M A V. A pesquisa qualitativa em Psicologia. São Paulo: Moraes, 1989.

${ }^{14}$ GONÇALVES, H., Corpo doente: Um estudo sobre a percepção corporal da tuberculose. In: Doença, Sofrimento, Perturbação: Perspectivas Etnográficas (L. F. Duarte \& O. F. Leal, org.). Rio de Janeiro: Fiocruz, 1998: 105-120.

${ }^{15}$ HUTEAU, M. Les mécanismes psychologiques de l'évolution des attitudes et des préférences vis à vis des activités professionnelles. L'Orientation Scolaire et Professionnelle, 1982, v.2: 107125.

${ }^{16}$ RODRIGUEZ, J. C. Tabu do Corpo. Rio de Janeiro: Achiamé, 1983

${ }^{17}$ MOSCOVICI, S. Representação social. Rio de Janeiro, Zahar, 2008

${ }^{18}$ LIBERMAN, F. O corpo como produção de subjetividade. Cadernos de Subjetividade PUCSão Paulo, 1997, v.5, nº 2 :12.

19 JODELET D, Representações sociais: um domínio em expressão. In :Jodelet, D (org). As representações sociais. Rio de Janeiro. Eduerj, 2002:17-44

${ }^{20}$ ALMEIDA, MVM, Corpo e arte em terapia ocupacional. Rio de Janeiro: Entrelivros, 2004.

${ }^{21}$ PORTO,A. Representações sociais da tuberculose: estigma e preconceito. Rev. Saúde Pública. 2007, vol.41, suppl.1: 43-49.

${ }^{22}$ BARBIER, R. A escuta sensível em educação. Cadernos do Anped, n. 5, 1993.

${ }^{23}$ OLIVEIRA, DC , A Enfermagem e as necessidades Humanas Básicas: o saber/fazer a partir das representações sociais, Tese (Concurso de professor Titular), Faculdade de Enfermagem, Universidade do Estado do Rio de Janeiro, Rio de Janeiro, 2001, p 242.

${ }^{24}$ TEDESCO, S. Tecendo a rede: trajetórias da saúde mental em São Paulo 1989-1996. Rev. Bras. Psiquiatr. São Paulo, 1999, v. 21, n. 3,. 
${ }^{25}$ GOFFMAN, E., Estigma. Buenos Aires: Amorrortu. 1970 .

${ }^{26}$ ROSSO CFW, COLLET N. Os enfermeiros e a prática de educação em saúde em municípios do interior paranaense. Revista Eletrônica de Enfermagem Goiânia; 1999 out-dez. 